Jurnal Penelitian Hasil Hutan

Forest Products Research Journal

Vol. 11 No. 5 (1993) pp. 205-208

\title{
PENINGKATAN RENDEMEN DAN DAYA SERAP ARANG AKTIF DENGAN CARA KIMIA DOSIS RENDAH DAN GASIFIKASI \\ (Improvement on recovery and quality of activated charcoal through low dossage chemical and gasification treatment) \\ Oleh/By
}

Hartoyo dan Gustan Pari

Summary

Study for improving the recovery and quality of activated charcoal through the combination of chemical and gasification treatments is presented in this paper. The material used in this experiments was charcoal derived from coconut shell. The material was immersed respectively in $\mathrm{NaOH}, \mathrm{Na}_{2} \mathrm{CO}_{3}, \mathrm{H}_{3} \mathrm{PO}_{4}$ and $\mathrm{ZnCl}_{2}$ for 24 hours. Charcoal activation was conduted by using steam or combination of steam and mixed $\mathrm{CO}_{2}$ and $\mathrm{N}_{2}$. The activated charcoal was produced in a stainless steel retort with electric heater at temperature of $900-1000^{\circ} \mathrm{C}$.

The result shows that the low dossage chemical treatment using $\mathrm{NaOH}$ at a concentration of $0,75 \%$, or $\mathrm{Na}_{2} \mathrm{CO}_{3}$ at a concentration of $0,75 \%$, or $\mathrm{ZnCl}_{2}$ at a conentration of $5 \%$, followed by activition by steam or the combination of steam and mixed $\mathrm{CO}_{2}$ and $\mathrm{N}_{2}$, could produce good.quality activated charcoal which fullfils the commercial standard according to JIS. The produced charcoal attained the iodine adsorptive capacity of more than $1050 \mathrm{mg} / \mathrm{g}$. By increasing the concentration of $\mathrm{ZnCl}_{2}$ to $10 \%$ or $\mathrm{H}_{3} \mathrm{PO}_{4}$ to $20 \%$. followed by steam activation at $900^{\circ} \mathrm{C}-1000^{\circ} \mathrm{C}$, the iodine adsorptive capacity increased to more than $1200 \mathrm{mg} / \mathrm{g}$.

\section{PENDAHULUAN}

Rujukan tentang pembuatan arang aktif yang berkualitas tinggi sudah cukup banyak tetapi hanya bersifat kualitatif dengan tidak ada kejelasan dalam proses pembuatannya baik secara teknis apalagi dukungan aspek ekonomis. Sebagai contoh peningkatan kualitas arang aktif bisa ditempuh melalui pemberian bahan kimia seperti $\mathrm{ZnCl}_{2}$ dan $\mathrm{H}_{3} \mathrm{PO}_{4}$ (Estudillo, Luis, Amio dan Tombolong 1977) serti uap panas $\left(\mathrm{H}_{2} \mathrm{O}\right)$, gas $\mathrm{CO}_{2}$ dan gas lainnya.

Masalah yang dihadapi dalam hubungannya dengan kualitas arang aktif dari bahan biomassa seperti tem'Irung kelapa dan kayu adalah bagaimana meningkatkan kualitas terutama daya adsorpsi dengan menggunakan bahan kimia yang murah dengan konsentrasi rendạh sehingga menguntungkan. Sifạt utama yang dapat digunakan untuk menilai kualitas arang aktif secara umum adalah kemampuan daya serap yang tinggi terhadap polutan atau zat beracun baik dalam bentuk gas maupun cairan. Umumnya arang aktif yang mempunyai daya serap yang dinyatakan terhadap iodium lebih besar dari $1000 \mathrm{mg} / \mathrm{g}$ lebih disukai terutama untuk kepentingan dalam industri.

Dalam tulisan ini akan disajikan hasil penelitian mengenai peningkatan rendemen dan daya serap arang aktif dari bahan tempurung kelapa dengan menggunakan bahan kimia dosis rendah dan uap panas. Di samping itu dicoba juga bahan gas $\mathrm{CO}_{2}$ dan $\mathrm{N}_{2}$ murni. Bila hal ini berhasil dapat digunakan gas $\mathrm{CO}_{2}$ dan Gas $\mathrm{N}_{2}$ yang berasal dari gas hasil pembakaran. Tujuan dari penelitian ini adalah menemukan bahan dan metode untuk menghasilkan arang aktif yang berkualitas tinggi yaitu yang mempunyai daya serap iodium lebih dari $1000 \mathrm{mg} / \mathrm{g}$.

\section{BAHAN DAN METODE}

Bahan baku yang digunakan dalam penelitian ini adalah arang dari tempurung kelapa yang diperoleh dari Jawa Barat. Bahan kimia yang digunakan adalah $\mathrm{H}_{3} \mathrm{PO}_{4} 5 \%$, $10 \%, 20 \%, \mathrm{ZnCl}_{2} 5 \%$ dan $10 \%, \mathrm{Na}_{2} \mathrm{CO}_{3} 0,75 \%$ dan $1,0 \%$ serta larutan $\mathrm{NaOH} 0,75 \%$. Proses aktifasi arang aktif dilakukan dengan 2 cara yaitu aktifasi dengan bahan kimia dan uap panas serta aktifasi dengan cara bahan kimia serta campuran uap panas dengan gas $\mathrm{N}_{2}$ dan $\mathrm{CO}_{2}$. Aktifasi dilakukan dalam retort yang terbuat dari baja tahan karat (stainless steel) dengan ukuran panjang $1,0 \mathrm{~m}$ dan diameter $5 \mathrm{~cm}$.

\section{A. Aritifasi Dengan Bahan Kimia dan Uap Panas.}

Dalam metode ini bahan baku direndam dalam larutan kimia selama 24 jam, setelah ditiriskan dan dikeringkan selanjutnya diaktivasi dengan cara mengalirkan uap panas ke dalam reaktor pada suhu $900^{\circ} \mathrm{C}-1000^{\circ} \mathrm{C}$. Laju alir uap panas dibuat tetap yaitu sebesar $0,5 \mathrm{~kg} / \mathrm{jam}$ Kondisi pengolahan aktifasi kimia dan uap panas yang diberikan tercantum pada Tabel 1 .

\section{B. Aktifasi Cara Kimia serta Campuran Uap Panas dan gas $\mathrm{N}_{2}$ serta $\mathrm{CO}_{2}$. \\ Dalam cara ini bahan baku direndam dalam larutan}


Tabel 1. Kondisi pengolahan aktifasi kjmia dan uap panas Table 1. Treatment condition of chencical and semn activution

\begin{tabular}{ccc}
\hline $\begin{array}{c}\text { Bahan kimia } \\
\text { (Chemical) }\end{array}$ & $\begin{array}{c}\text { Konsentrasi } \\
\text { (Concentration) } \\
\%\end{array}$ & $\begin{array}{c}\text { Waktu reaksi } \\
\text { (Reaction time) } \\
\text { menit (minute) }\end{array}$ \\
\hline \multirow{2}{*}{$\mathrm{ZnC}_{2}$} & 5 & 90 \\
& 5 & 120 \\
& 5 & 135 \\
$\mathrm{H}_{3} \mathrm{PO}_{4}$ & 10 & 105 \\
& 5 & 120 \\
& 10 & 120 \\
& 20 & 105 \\
$\mathrm{Na}_{2} \mathrm{CO}_{3}$ & 20 & 120 \\
& 20 & 135 \\
$\mathrm{NaOH}$ & 0.75 & 105 \\
& 0.75 & 120 \\
$\mathrm{Kontrol}$ (Control) uap (steam) & 1 & 105 \\
& 0.75 & 120 \\
\end{tabular}

kimia selama 24 jam, setelah ditiriskan dan dikeringkan selanjutnya diaktitkan dengan taengalirkan campuran uap panas dan gas $\mathrm{N}_{2}$ serta $\mathrm{CO}_{2}$ padá suhu $900^{\circ} \mathrm{C}-1000^{\circ} \mathrm{C}$. Waktu reaksi yang diberikan dibuat tetap yaitu selama 105 menit. Aktifasi dilakukan dengan mengalirkan uap panas dengan laju alir $0,5 \mathrm{~kg} / \mathrm{jam}$ selama, 75 menit kemudian dialirkan campuran gas $\mathrm{CO}_{2}$ dan $\mathrm{N}_{2}$ selama 30 menit dengan laju alir 4 mbarjam.

Kualitas arang aktif yang dihasilkan ditetapkan daya serap terhadap larutan iodium berdasarkan standar SII (Anonith, 1989) dan AWWA (Anonim, 1978) serta rendemon ak aktif: Hasilnya dibandingkan dengan standri Jepang (Anonim; 1967).

Tabel 2. Kondisi pengolahan aktifasi kimia serta campuran uap panas dan gas $\mathrm{N}_{2}$ serta $\mathrm{CO}_{2}$

Table 2 Treatment condition of chenoical and mixture of steam and gas $\mathrm{N}_{2} \mathrm{COO}_{2}$

\begin{tabular}{ccc}
\hline $\begin{array}{c}\text { Bahan kimia } \\
\text { (Chemical) }\end{array}$ & $\begin{array}{c}\text { Konsentrasi } \\
\text { (Concentration) } \\
\%\end{array}$ & $\begin{array}{c}\text { Waktu reaksi } \\
\text { (Reaction time) } \\
\text { menit (juinute) }\end{array}$ \\
\hline
\end{tabular}

\begin{tabular}{lcc}
\hline & & \\
\hline $\mathrm{H}_{3} \mathrm{PO}_{4}$ & 20 & 105 \\
$\mathrm{Na}_{2} \mathrm{CO}_{3}$ & 0.75 & 105 \\
$\mathrm{NaOH}$ & 1 & 105 \\
$\mathrm{Kontrol}$ (Control) uap (steam) & 0.75 & 105 \\
\hline
\end{tabular}

Tabel 3. Daya serap arang aktif

Table 3. Activated charcoul adsorption-

\begin{tabular}{ccccc}
\hline $\begin{array}{l}\text { Bahan kimia } \\
\text { (Chemical) }\end{array}$ & $\begin{array}{c}\text { Konsentrasi } \\
\text { (Concentration) }\end{array}$ & $\begin{array}{c}\text { Waktu reaksi } \\
\text { (Reaction time) }\end{array}$ & $\begin{array}{c}\text { Rendemen } \\
\text { (Yielá) }\end{array}$ & $\begin{array}{c}\text { Daya sertip iod* } \\
\text { (lod adsorption) }\end{array}$ \\
\hline
\end{tabular}

A. Altivad Kimia Uap (Steom \& Chamical Activestion)

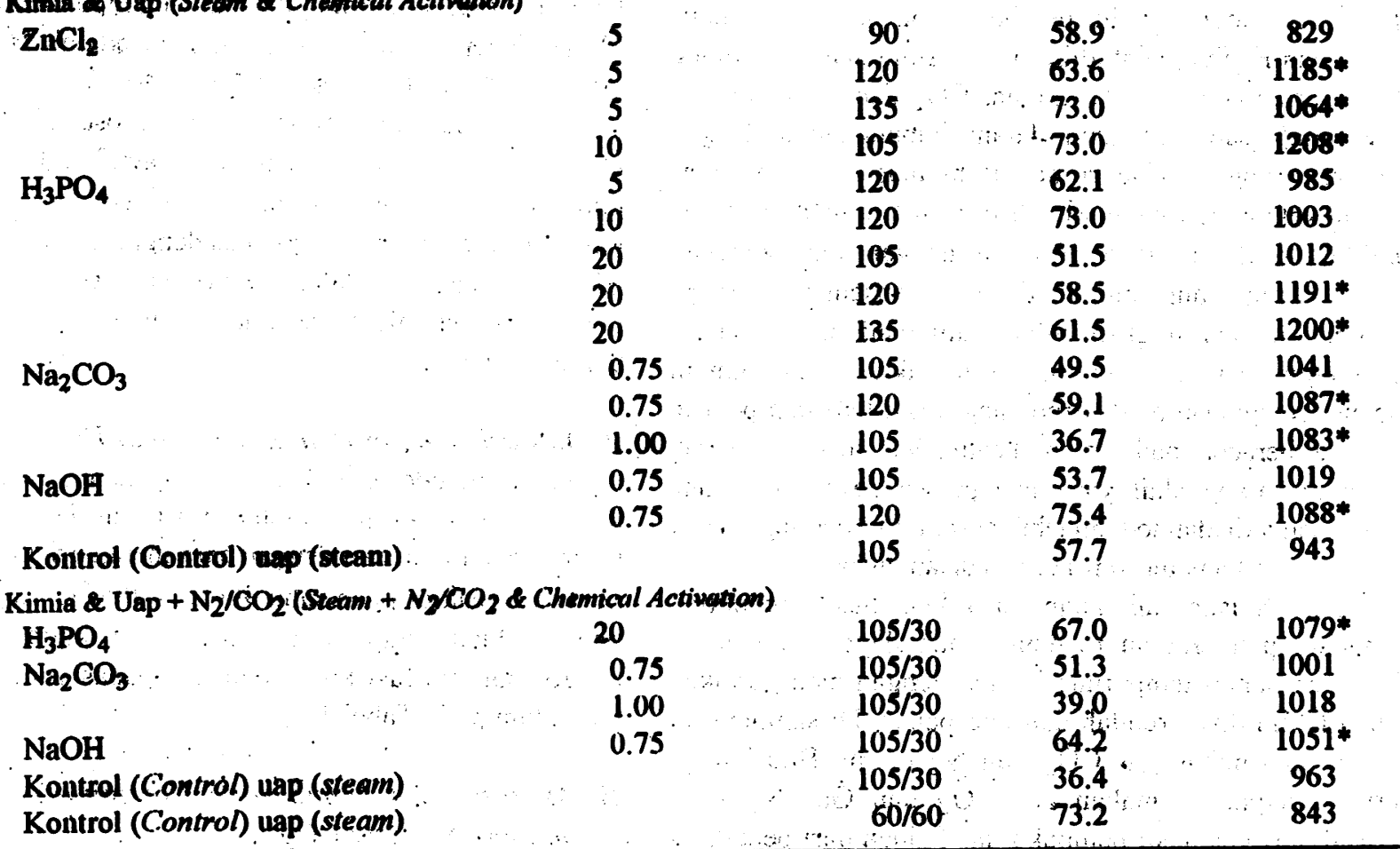

Keterangan (Remark) : * Mememud syarat standar Jepang (Conform with Japanese standard) = $1050 \mathrm{mg} / \mathrm{g}$ 


\section{HASIL DAN PEMBAHASAN}

Hasil peningkatan kualitas arang aktif dengan sistem gasifikasi dan kimia tercantum pada Tabel 3.

\section{A. Kendemen Arang Aktif}

Berdasarkan Tabel 3 terlihat bahwa secara keseluruhan arang aktif hasil penelitian dengan cara kimia serta campuran uap panás dan $\mathrm{N}_{2}$ serta $\mathrm{CO}_{2}$ dengan waktu reaksi yang sama (105 menit) menghasilkan rendemen arang aktif (39,0 - $67 \%)$ yang lebih besar daripada rendemen arang aktif yang hanya dialiri uap panas (36,7 $51,5 \%)$. Besarnya rendemen ini mungkin disebabkan oleh gas $\mathrm{CO}_{2}$ merupakan oksidator lemah dan gas $\mathrm{N}_{2}$ yang bersifat lembam (inert) ternyata dapat mengurangi reaksi korosif.

Apabila hasil ini dibandingkan dengan arang aktif yang tidak direndam bahan kimia (Tabel 3) dalam hal ini hanya dialiri campuran uap panas dan $\mathrm{N}_{2}$ serta $\mathrm{CO}_{2}$ rendemen arang aktif yang dihasilkan lebih kecil. Hal ini memberikan gambaran bahwa penambahan bahan kimia dapat memperlambat laju kecepatan reaksi pada waktu proses oksidasi. Hasil ini sesuai dengan yang dilakukan oleh Hudaya dan Hartoyo (1990) yang menyimpulkan bahwa rendemen arang aktif yang dihasilkan dengan cara kimia lebih besar dibandingkan dengan cara aktivasi uap.

\section{B. Daya Serap Terhadap Iodium}

Penetapan daya serap arang aktif terhadap iodium merupakan persyaratan umum untuk menilai kualitas arang aktif. American Water Works Association/AWWA (Anonim , 1978) mensyaratkan daya serap arang aktif terhadap iodium sebesar $500 \mathrm{mg} / \mathrm{g}$, Standar Industri Indonesia/SII (Anonim, 1989) $750 \mathrm{mg} / \mathrm{g}$ dan standar Jepang (Anonim, 1967) sebesar 1050 mg/g. Berdasarkan Tabel 3 terlihat bahwa daya serap arang aktif terhadap iodium yang dihasilkan dalam penelitian ini semuanya memenuhi persyaratan kualitas arang aktif yang ditetapkan oleh AWWA dan SII serta sebagian perlakuan yang memenuhi standar Jepang (JIS).

Arang aktif yang dihasilkan dengan cara kimia serta campuran uap panas dan $\mathrm{N}_{2}$ serta $\mathrm{CO}_{2}$ terutama untuk yang direndam $\mathrm{H}_{3} \mathrm{PO}_{4}(20 \%)$ dan $\mathrm{NaOH}(0,75 \%)$ dengan waktu reaksi 105 menit dapat meningkatkan daya serap terhadap iodium sebesar $6,2-8,4 \%$ dibandingkan terhadap arang aktif yang dihasilkan dengan cara kimia dan uap panas pada kondisi yang sama. Selain itu dapat meningkat sampai 8,3 - 10,7\% terhadap arang aktif yang tidak direndam bahan kimia. Tetapi sebaliknya untuk arang aktif yang direndam $\mathrm{Na}_{2} \mathrm{CO}_{3}$ dengan konsentrasi $0,75 \%$ dan $1,00 \%$ pemberian gas $\mathrm{Na}_{2} / \mathrm{CO}_{2}$ menurunkan daya serap terhadap iodium dari $1041 \mathrm{mg} / \mathrm{g}$ menjadi 1001 $\mathrm{mg} / \mathrm{g}$ dan dari $1083 \mathrm{mg} / \mathrm{g}$ menjadi $1018 \mathrm{mg} / \mathrm{g}$. Turunnya daya serap ini mungkin disebabkan adanya pertambahan gas $\mathrm{CO}_{2}$ dari hasil degradasi $\mathrm{Na}_{2} \mathrm{CO}_{3}$ pada suhu tinggi sehingga secara keseluruhan jumlah gas $\mathrm{CO}_{2}$ meningkat. Meningkatnya $\mathrm{CO}_{2}$ dalam atmosfir aktifasi akan meningkatkan daya oksidasi sehingga menyebabkan kerusakan dinding pori dan berarti menurunkan luas permukaan (surface area) dinding pori. Namun demikian apabila dibandingkan dengan arang aktif yang tidak direndam bahan kimia (Tabel 3) daya serapnya meningkat sebesar $5,3 \%$. Hal ini menunjukkan bahwa bahan kimia yang digunakan selain berfungsi sebagai katalis juga dapat menyerap gas yang dihasilkan dari proses karbonisasi arang seperti gas $\mathrm{SO}_{2}, \mathrm{NO}_{2}$, asam nitrat dan asam asetat juga dapat menghilangkan senyawa hidrokarbon yang melapisi permukaan arang (Jacob dan Morris 1953). Dalam penelitian ini didapatkan daya serap arang aktif terhadap iodiumnya hampir $100 \%$ yaitu arang aktif yang direndam dalam larutan $\mathrm{ZnCl}_{2} \quad 10 \%$ dengan waktu reaksi 105 menit dan $\mathrm{H}_{3} \mathrm{PO}_{4} 20 \%$ dengan waktu reaksi 135 menit menghasilkan daya serap sebesar $1208,9 \mathrm{mg} / \mathrm{g}$ dan $1200,3 \mathrm{mg} / \mathrm{m}$. Angka ini tidak jauh berbeda dengan arang aktif buatan Jerman (merck) dengan harga jual Rp. $154.100 / \mathrm{kg}$ yang daya serapnya $1200 \mathrm{mg} / \mathrm{g}$. Walaupun pemakaian bahan kimia ini mahal tetapi mengingat harga jualnya yang tinggi maka perlu dinilai segi ekonomisnya.

\section{KESIMPULAN DAN SARAN}

\section{A. Kesimpuian}

1. Pemberian perlakuan aktivasi dengan cara uap panas dan bahan kimia dosis rendah yaitu $\mathrm{NaOH} 0,75 \%$. $\mathrm{ZnCl}_{2} 5 \%$ dan $\mathrm{Na}_{2} \mathrm{CO}_{3} \quad 0,75 \%, 1,0 \%$ ternyata dapat meningkatkan rendemen dan daya serap iodium lebih besar dari $1000 \mathrm{mg} / \mathrm{g}$.

2. Pemberian perlakuan kombinasi dengan penambahan campuran gas $\mathrm{CO}_{2}$ dan $\mathrm{N}_{2}$ untuk lebih meningkatkan daya serap arang aktif ternyata juga dapat meningkat untuk arang aktif yang menggunakan bahan kimia $\mathrm{NaOH}$ dan $\mathrm{H}_{3} \mathrm{PO}_{4}$ tetapi tidak untuk $\mathrm{Na}_{2} \mathrm{CO}_{3}$.

3. Penggunaan bahan kimia $\mathrm{ZnCl}_{2} \quad 10 \%$ atau $\mathrm{H}_{3} \mathrm{PO}_{4}$ $20 \%$ yang diaktifasi dengan uap panas pada suhu 900 - $1000{ }^{\circ} \mathrm{C}$ dengan waktu reaksi masing- masing 105 dain 135 menit menghasilkan arang aktif yang mempunyai daya serap terhadap iodium lebih besar dari $1200 \mathrm{mg} / \mathrm{g}$

\section{B. Saran}

1. Untuk penggunaan bahan kimia $\mathrm{ZnCl}_{2}$ dan $\mathrm{H}_{3} \mathrm{PO}_{4}$ yang relatif mahal perlu dinilai dari segi ekonominya mengingat dapat menghasilkan daya serap yang sangat tinggi. 
2. Untuk penggunaan bahan kmia yang harganya relatif murah seperti $\mathrm{NaOH}$ dan $\mathrm{Na}_{2} \mathrm{CO}_{3}$ bisa diterapkan untuk tujuan penggunaan dalam industri.

\section{DAFTAR PUSTAKA}

Anonim. 1967. Japanese Industrial Standartd. Testing Method for Powdered Activated Carbon. JIS K 1474. Japanese Standards Association, Tokyo.

1978. American Water Works Association (AWWA) Standar for Powdered Activated Carbon. B 600-78. Coloraḍ.
1989. Mutu dan Cara Uji Arang Aktif Standar Industri Indonesia (SII) 0258-89. Departemen Perindustrian, Jakarta.

Estudillo, J.M., S. Luis, E.C. Amio and F.N. Tamolang. 1977. Charcoal Production and Utilization of Coconut Shells and Trunk in The Philippines. Forest Products Research. Madison.

Hudaya, N dan Hartoyo. 1990. Pembuatan arang aktif dari tempurung biji-bijian asal tanaman hutan dan perkebunan. Jurnal Penelitian hasil Hutan 8(4) : 146 150.

Jacob and Morris. 1953. Chemical Analysis of Industrial Solvents. Interscience Publisher Inc. New York. 